Introduction Bacterial vaginosis (BV) is a common vaginal infection, causing an abnormal vaginal discharge and/or odour in up to $50 \%$ of sufferers. Recurrence is common following recommended treatment. Increasing evidence suggests BV may be sexually transmitted, however causative agents for sexual transmission have not been verified. The aim of this study was to explore women's experiences of recurrent BV. This paper reports on findings relating to women's views and experiences around the causes and triggers of recurrent BV.

Methods Thirty five women were interviewed face-to-face or by phone about their experience of recurrent BV. Interviews took between 20-45 min. All interviews were digitally recorded, transcribed verbatim and imported into N-Vivo 9 for thematic analysis.

Results The majority of women attributed their BV episodes to some form of sexual contact or activity including unprotected sex, sex with casual partners, sex with an untreated female partner, oral sex or frequent sex. Some women reported a combination of sexual and lifestyle triggers however only a few women did not feel that some form of sexual contact had triggered their episodes of BV. While most women attributed their BV to some form of sexual contact they generally did not consider it an STI. Women used a range of self-help remedies in an attempt to treat BV symptoms and prevent further recurrences however most remedies were ineffective and at time exacerbated symptoms.

Conclusion Most women felt that their episodes of recurrent BV had been caused or triggered by some form of sexual contact. This study is one of the first studies to explore women's views and experiences around BV transmission. Further large scale studies are required to determine if women from diverse populations report similar experiences around BV transmission.

Disclosure of interest statement Dr. Jade Bilardi is in receipt of an NHMRC early career fellowship. There are no other competing interests.

\section{P14.06 A CHARACTERISATION OF CONCURRENT PARTNERSHIPS IN CAPE TOWN, SOUTH AFRICA}

${ }^{1,2} \mathrm{R}$ Beauclair*, ${ }^{3,4} \mathrm{~N}$ Hens, ${ }^{1,2} \mathrm{~W}$ Delva. ${ }^{1} T$ The South African Department of Science and Technology/National Research Foundation (DST/NRF), Centre of Excellence in Epidemiological Modelling and Analysis (SACEMA), Stellenbosch University, Stellenbosch, South Africa; ${ }^{2}$ International Centre for Reproductive Health, Ghent University, Gent, Belgium; ${ }^{3}$ Center for Statistics, Hasselt University, Diepenbeek, Belgium; ${ }^{4}$ Centre for Health Economic Research and Modelling Infectious Diseases, Vaccine and Infectious Disease Institute, University of Antwerp, Wirijik, Belgium

\subsection{6/sextrans-2015-052270.518}

Background Concurrent partnerships (CPs) are hypothesised to be a risk factor for transmitting HIV. Some have noted that their impact on the epidemic depends upon how common they are in populations, the average number of CPs an individual has, and the amount of time they overlap. However, estimates of prevalence of CPs in Southern Africa vary widely, and the length of overlap in these relationships is inadequately described.

Methods We conducted a sexual behaviour survey $(n=878)$ in Cape Town, South Africa, using Audio Computer-Assisted SelfInterviewing to collect sexual relationship histories on partners in the previous year. Using the beginning and end dates for the partnerships, we calculated the point prevalence, 1-year cumulative prevalence and degree distribution of $\mathrm{CPs}$, as well as the duration of overlap for relationships begun in the previous year. Linear and binomial regression models were used to quantify race and gender differences in the duration of overlap and relative risk of having CPs in the past year.

Results The overall point prevalence of CPs 6 months before the survey was $8.4 \%$ : $13.4 \%$ for black men, $1.9 \%$ for coloured men, $7.8 \%$ black women, and $5.6 \%$ for coloured women. The 1 -year cumulative prevalence for all sexually active participants was 25.4\%. The median duration of overlap in CPs was 7.5 weeks. Women had less risk of CPs in the previous year than men (RR 0.43; 95\% CI: $0.32-0.57$ ) and black participants were more at risk than coloured participants (RR 1.86; 95\% CI: 1.17-2.97). Overall, of those who had 2 or more relationships in the past year, $85.9 \%$ had concurrent as opposed to serially monogamous partnerships.

Conclusions Our results indicate that in this population the prevalence of CPs is relatively high and is characterised by overlaps of long duration, implying there may be opportunities for HIV to be transmitted to CPs.

Disclosure of interest statement We have no commercial contributions to disclose.

\section{P14.07 SEXUAL HEALTH PROMOTION AND STI PREVENTION ON THE MARGINS: KINK, BDSM, AND SEXUALLY ADVENTUROUS WOMEN}

$\checkmark$ McGregor*. AIDS Council of NSW (ACON)

\subsection{6/sextrans-2015-052270.519}

Introduction Claude is a highly innovative sexual health promotion website and service for women who play with women, primarily within a kink or BDSM context. ACON has a long history of working with marginalised sexual communities and identified priority populations. Recent research has identified women connected with kink or BDSM scenes engage in sexual practices such as blood play (for example piercing and cutting), fisting, and sex with multiple partners, which have higher risks for both STIs and BBVs. The website iloveclaude.com provides targeted sexual health information, safety tips, free play packs (including safe sex resources, information, and materials), and a list of queer- and kink-friendly health services. Its innovation lies in its use of creative pursuits such as photography, writing, performance and video art, and the ways in which the strategies for health promotion focus on sexual practice rather than sexual identity.

This paper will discuss the initial qualitative research that led to the formation of Claude: Kath Albury's 2011 "Safer Sex Beliefs and Practices in Multi-Partner Heterosexuals". This research concluded that women within the swingers, kink, and BDSM scenes were at a higher risk of STI and BBV transmission. This paper will outline the barriers to safe sex practice identified by Albury's research, and explain how Claude and the website iloveclaude.com were formulated as a response to these issues. This paper will focus on two of the main barriers to safe practice: 1) Discrepancy between self-identification as heterosexual, and the actual nature of sexual practice; and 2) Lack of access to specific targeted sexual health resources. Outlining how the Claude project was formulated to implement recommendations from this research regarding STI education and prevention, this paper will discuss the challenges of sexual health promotion within a diverse and often marginalised community.

Claude is run by the ACON Lesbian and Same Sex Attracted Women's Sexual Health Project. 
Disclosure of interest statement ACON acknowledges its primary funder, the NSW Ministry of Health. ACON has not received pharmaceutical grants for this work.

\section{P14.08 COMPARATIVE STUDY OF VULNERABILITY OF CIRCUMCISION AMONG WOMEN OF KENYA AND NIGERIA}

Ankita Siddhanta*. International Institute for Population Sciences, India

10.1136/sextrans-2015-052270.520

Introduction Female circumcision is a phenomenon specific to Africa continent. The main objective of study is to understand the determinant affecting female circumcision in the two selected African countries of Kenya and Nigeria.

Methods Bivariate and Multivariate techniques were used to analyse DHS Data for this study.

Results Most Kenyan women (90\%) are of the view that circumcision should be discontinued compared to $74 \%$ in Nigeria. In both the countries, with increasing age and education the attitude and perception of the women towards the continuation of the service is getting negative $(\mathrm{P}<0.01)$. It is found that high percentage $(86.6 \%)$ of women from Christian community in Kenya as compared to only $66 \%$ in Nigeria believe that this tradition has no benefit. In Kenya, circumcision among Islam women $(55 \%)$ doubles than the Christians whereas in Nigeria, this practice among the Christians is equally high (47.3\%). The Islam women in Kenya are 2.7 times more likely than the Christians to say that this practice should be continued and 35\% want her daughter to be circumcised compared to only $5.7 \%$ in Nigeria. Surprisingly, $17 \%$ women in Kenya and $25 \%$ in Nigeria experienced circumcision even after marriage thus flouting the popular belief, that infibulated genitalia before marriage is much preferred option. Circumcised women are 11 times and 21 times more likely in Kenya and Nigeria respectively than uncircumcised women to want the persistence of circumcision.

Conclusion Aforesaid results clearly points out that the Nigerian women faces more circumcision and are exposed conformed to socially constructed norms. The findings reiterated the basic nature of human where we find that the women who went through the pain want other women also to be prisoners of circumcised pain. Expansion of reproductive health policies, planning and programming should include Circumcision to address the vulnerabilities.

Disclosure of interest statement Not applicable.

\section{P14.09 ADVANCING HIV AND STI JUSTICE: THE KEY ROLE OF SCIENCE AND SCIENTISTS IN ENDING OVERLY BROAD HIV AND STI CRIMINALISATION}

EJ Bernard*. HIV Justice Network, UK

\subsection{6/sextrans-2015-052270.52}

Introduction Overly broad laws criminalising HIV and/or STI non-disclosure, exposure and/or non-intentional transmission exist in countries across the globe. Although some laws are HIVspecific, many prosecutions take place under general criminal or public health laws which allow for STI-related prosecutions. Although most attention has focused on HIV-related prosecutions, a growing number of prosecutions and new or proposed laws also relate to other STIs.
Methods A desk review of criminal proceedings, policy documents and newspaper reports related to HIV and STI-related laws and prosecutions in 2014-15.

Results Most reported HIV-related prosecutions continue to take place in North America, but are also being reported in every region of the world. Whilst international and local advocacy has delivered significant challenges to inappropriate and overly broad HIV-specific laws in a number of jurisdictions, and the science of HIV risk, harm and proof has had a significant impact on law and policy in some North American and Western European jurisdictions, new overly broad HIV-specific or STI-related laws continue to be proposed or enacted. Many HIV-related laws and prosecutions continue to inappropriately focus on spitting or non-disclosure even when no transmission is alleged, whilst others ignore the HIV prevention effect of condoms and/ or antiretroviral therapy. In addition, laws and prosecutions for other STIs, including for gonorrhoea, herpes, and syphilis, as well as sexually transmitted hepatitis B and C, and potentially even Ebola, are increasing.

Conclusion Criminal justice actors and law- and policymakers struggle with the science around HIV and STI risks, harm and proof, and are unaware of the unintended deleterious impacts of such laws and prosecutions. Scientists and clinicians have a key role to play to influence individual cases and broader laws and policies relating to prosecutions for HIV and STIs non-disclosure, exposure and/or transmission in order to improve both public health and human rights.

Disclosure of interest statement The HIV Justice Network is funded by Monument Trust, UK. No pharmaceutical grants were received in the development of this study.

\section{P14.10 FIGHT FOR THE RIGHT TO HEALTH CARE SERVICES FOR PEOPLE WITH HIV}

Dion Nuryadi*

\subsection{6/sextrans-2015-052270.522}

Background By September 2013, 70\% of districts/cities in Indonesia reported 45,650 HIV cases. The discrepancy between the estimated 500,000 HIV people and reported cases shows there is a great number of hidden PLHIV not reached by empowerment programs thus causing them experiencing low life-quality.

Description In 2012-2013, we strengthened organising PLHIV agreed to establish JAPI (Indonesian Action Network for Change), becoming a political agent of change; programs include: facilitating and publishing homebased-care module, together with $\mathrm{MoH}$ and IPPA, supervision and M\&E provincialvisits, expanding the network to include women, MSM, Transgender, IDUs human rights, environmental and global justice activists. In 2013-2014 JAPI's advocacy through series of workshop, executive consultations and campaign to fight for rights to health services for PLHIV in Indonesia. JAPI has published two training modules: (1) Psychosocial support for PLHIV (2) Community organising. JAPI also grew stronger becoming Evaluator for Access to health Team-members with $\mathrm{MoH}$ and national facilitator for Social analysis and positive prevention. There are 82 groups (GF/Implementing Units) in 12(of 33) provinces with 110 PLHIV -peer-facilitators supporting 39,056 PLHIV.

Lessons learned Through intensive PLHIV Community-Organising and training, PLHIV groups evolved from being objects of projects, turn into subjects in the AIDS response. 